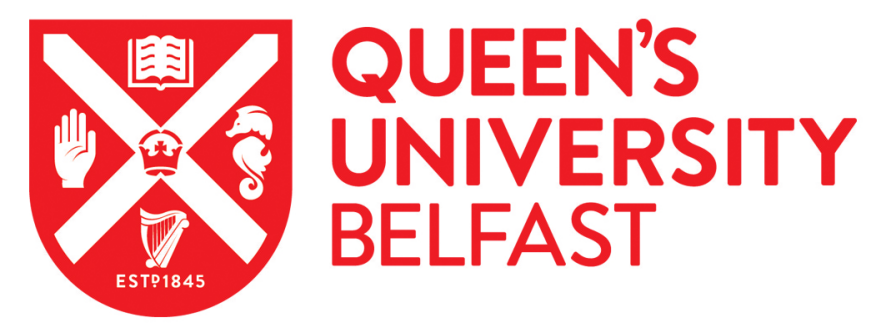

\title{
Experiencing Regret About a Choice Helps Children Learn to Delay Gratification
}

McCormack, T., O'Connor, E., Cherry, J., Beck, S. R., \& Feeney, A. (2019). Experiencing Regret About a Choice Helps Children Learn to Delay Gratification. Journal of Experimental Child Psychology, 179, 162-175.

Published in:

Journal of Experimental Child Psychology

Document Version:

Peer reviewed version

Queen's University Belfast - Research Portal:

Link to publication record in Queen's University Belfast Research Portal

Publisher rights

(C) 2018 Elsevier Inc.

This manuscript version is made available under the CC-BY-NC-ND 4.0 license http://creativecommons.org/licenses/by-nc-nd/4.0/,which permits distribution and reproduction for noncommercial purposes, provided the author and source are cited

\section{General rights}

Copyright for the publications made accessible via the Queen's University Belfast Research Portal is retained by the author(s) and / or other copyright owners and it is a condition of accessing these publications that users recognise and abide by the legal requirements associated with these rights.

Take down policy

The Research Portal is Queen's institutional repository that provides access to Queen's research output. Every effort has been made to ensure that content in the Research Portal does not infringe any person's rights, or applicable UK laws. If you discover content in the Research Portal that you believe breaches copyright or violates any law, please contact openaccess@qub.ac.uk. 


\title{
Authors' accepted version. This manuscript has not been copyedited.
}

Experiencing Regret About a Choice Helps Children Learn to Delay Gratification Teresa McCormack ${ }^{1}$ Eimear O’Connor ${ }^{1} \quad$ Jessica Cherry $^{1} \quad$ Sarah R. Beck $^{2}$

\author{
Aidan Feeney ${ }^{1}$ \\ ${ }^{1}$ Queen's University Belfast \\ ${ }^{2}$ University of Birmingham
}

Author Note

Teresa McCormack, Eimear O’Connor, Jessica Cherry, and Aidan Feeney, School of Psychology, Queen's University Belfast, Belfast BT7 1NN; Sarah Beck, School of Psychology, University of Birmingham, Edgbaston, Birmingham, B15 2TT.

This research was supported by a grant from the Economic and Social Research Council, UK, grant number ES/K000411/1.

Correspondence concerning this article should be addressed to Teresa McCormack, School of Psychology, Queen's University Belfast, Belfast BT7 1NN, Northern Ireland, UK. Email: t.mccormack@qub.ac.uk 


\begin{abstract}
Six-to-seven-year-olds decided whether to wait for a short delay to win a prize or for a longer period to win a different prize. Those who chose to take their prize after a short delay won two candies, but were shown that they would have won four candies if they had waited longer. We measured whether children regretted their choice not to wait. The next day, children were faced with the same choice again. Children who regretted choosing the short delay on Day 1 were more likely to delay gratification on Day 2 than children who had not regretted their previous choice. In a second study, we replicated this finding while controlling for intellectual ability and children's preference for 4 over 2 candies. This suggests that experiencing regret about a choice not to wait assists children in delaying gratification when faced with the same choice again.
\end{abstract}

Keywords: Delay of gratification; regret; counterfactuals; cognitive development 


\section{Experiencing Regret About a Choice Helps Children Learn to Delay Gratification}

The ability to delay gratification has been of great interest to psychologists, in part because measures of this ability at preschool age are predictive of important outcomes in later life (Mischel, 2014). Delaying gratification is seen as an important aspect of emerging selfcontrol, with children's ability to delay gratification improving as they get older (Mischel \& Metzner, 1962; Tobin \& Graziano, 2010). The development of the ability to delay gratification seems to be distinct from a number of other aspects of cognitive development (Atance \& Jackson, 2009; Hongwanishkul, Happaney, Lee, \& Zelazo, 2005; Jahromi, \& Stifter, 2008; Kim, Nordling, Yoon, Boldt, \& Kochanska, 2013; though see Yu, Kam \& Lee, 2016). Delay of gratification has been conceptualized as a type of "hot" executive function that has an affective component and may rely on different mechanisms than the purely cognitive "cold" executive functions (Welsh \& Peterson, 2014; Zelazo \& Carlson, 2012; Zelazo \& Muller, 2002). It has been suggested that developmental changes in delayed gratification are closely linked to emotional development (Hongwanishkul et al., 2005; Kim et al., 2013). However, although it is known that children's concurrent emotional state can influence the likelihood that they delay gratification (Moore, Clyburn, \& Underwood, 1976; Shimoni, Asbe, Eyal, \& Berger, 2016; Yates, Lippett, \& Yates, 1981) we do not know the means by which emotional development facilitates delayed gratification. Moreover, there is still uncertainty about how cognitive changes contribute to developmental improvements in delayed gratification (Mischel et al., 2011; Yu et al., 2016).

The current study explores one candidate contributory mechanism that has both cognitive and affective components: the emergence of the counterfactual emotion of regret. In adult decision making, regret is viewed as being a functional emotion that, although unpleasant, plays a key role in supporting better decision making (Roese, 2005; Zeelenberg \& 
Pieters, 2007). If this is correct, then a straightforward prediction is that children's decision making will improve once they begin to experience regret. There is some, albeit limited, evidence that this is indeed the case in scenarios where children make very simple decisions that do not involve delay of reward (O'Connor, McCormack, \& Feeney, 2014). O'Connor et al. showed that children who experience regret about a choice (selecting between two colored boxes to get a reward) were more likely to appropriately switch choices when given the opportunity to choose again. They interpreted their findings as indicating that the experience of regret helps children switch their choices adaptively. This finding is consistent with theoretical claims about the experience of regret that suggest that its role is to facilitate switching of choices (Connolly \& Zeelenberg, 2002; Zeelenberg \& Pieters, 2007; Zeelenberg, Van Dijk, Manstead, \& van der Pligt, 2000). It is not known, however, if the experience of regret impacts on other types of decision making in children. The current study tested the hypothesis that children who experienced regret about failing to wait for a longer delay to get a reward were more likely to subsequently wait when faced with the same choice again.

\section{The development of regret}

Regret is a counterfactual emotion: it requires being able to think about not only what has happened as a result of one's choice, but what could have happened if one had chosen differently (Beck, Riggs, \& Burns, 2011). Although there is considerable debate over when children can first engage in counterfactual thinking (Beck \& Riggs, 2014; Harris, German, \& Mills, 1996; Rafetseder \& Perner, 2014; Weisberg \& Gopnik, 2013), many researchers believe that children aged 4 to 5 years are capable of this sort of thought (e.g., Drayton, Turley-Ames, \& Guajardo, 2011; German \& Nichols, 2003; Sobel, 2011). However, it cannot be straightforwardly assumed that children of this age can also experience regret. Beck et al. argued that the ability to experience regret may emerge somewhat later, because not only do children need to be able to think counterfactually in order to experience regret, they also need 
to be able to evaluatively compare the actual and counterfactual outcomes. Given this, Beck et al. (2011) suggested that later-developing aspects of 'cool' cognitive control might be related to the ability to experience regret. Consistent with Beck et al.'s suggestion, Burns, Riggs and Beck (2012) reported that attentional flexibility was predictive of children's ability to experience regret.

In line with the idea that regret is a relatively late developing emotion, a variety of studies have suggested that children do not typically experience regret until around 5 to 7 years (Burns et al., 2012; O’Connor et al., 2014; O’Connor, McCormack, \& Feeney, 2012; Van Duijvenvoorde, Huizenga, \& Jansen, 2014; Uprichard \& McCormack, 2018; Weisberg \& Beck, 2010, 2012). These studies differ in their procedural details, but all involve children choosing between two boxes to get a reward. Children are shown initially that there is a reward inside their chosen box (e.g., one sticker), and are asked to rate how happy they feel about this reward using a scale. They are then shown that the unchosen box contained a better reward (e.g., 5 stickers), and asked to rate their happiness again. Children are assumed to experience regret if they feel sadder having seen what they would have obtained if that had chosen differently. The proportion of children who report feeling sadder increases developmentally (Burns et al., 2012; Feeney, Travers, O’Connor, Beck, \& McCormack, 2018; O’Connor et al., 2012, 2014; Van Duijvenvoorde et al., 2014).

Although the ability to experience regret seems to emerge around 5-7 years, there are further important developmental changes in children's ability to predict and understand regret (Ferrell, Guttentag, \& Gredlein, 2009; Guttentag \& Ferrell, 2008; Weisberg \& Beck, 2010). It is not until children are around 8 years of age that they are able to correctly anticipate that they will experience regret (McCormack \& Feeney, 2015). McCormack and Feeney asked children to predict how they would feel if an unchosen box contained a better reward than the box they had chosen, and found that 6- to 7-year-olds were unable to predict that they would 
feel sadder, even though the majority of children of this age will report feeling sadder when they actually are shown that they made a sub-optional choice. Anticipation of regret involves not just evaluatively comparing an actual with a counterfactual outcome, it involves imagining future possible outcomes and grasping their emotional significance. This ability seems to develop a year or two later than the ability to experience regret once outcomes are known. Similarly, it is not until children are around 8 that they understand the conditions under which regret is experienced, allowing them to predict when others will experience this emotion (Ferrell et al., 2009).

The distinction between being able to experience regret and to anticipate it is an important one, given the existing decision making literature, where it commonly assumed that regret affects decision making primarily through the anticipation and thus avoidance of future regret (e.g., Larrick \& Boles, 1995; Mellers, Schwartz, \& Ritov, 1999; Zeelenberg, 1999; Zeelenberg \& Pieters, 2007). It seems particularly plausible that anticipation of regret might act as a mechanism for helping delay gratification: when faced with the choice over whether to wait, one may anticipate the future regret one will feel when succumbing to the temptation of immediate rather than delayed reward and decide to delay gratification accordingly. If, as hypothesized, there is an association between regret and delayed gratification in children, one issue is whether such a link directly reflects the effect of experiencing regret on behavior, or in fact reflects the ability of some children to anticipate and thus avoid future regret. Answering this question involves measuring not just whether children can experience regret, but also whether they can anticipate this emotion.

\section{The current study}

In this study, we tested the hypothesis that experiencing regret helps children learn to delay gratification. We used a sample of children aged 6 to 7 years because in this age group some children will experience regret about a poor choice but some will not, whereas the vast 
majority of older children will experience regret. We first allowed children to choose between waiting for a short or a long delay for a reward; the size of the reward available at the long delay was twice that available at the short delay. However, at this stage of the task children did not know the nature of the rewards available at each delay. This meant that after children had made their choice and received their reward, we were able to demonstrate to them what they would have won if they had chosen differently (i.e., the counterfactual alternative). We then measured whether they regretted their choice if they had chosen to wait only for a short delay (which in fact the majority of children had). We subsequently re-tested the children the next day by providing them with an identical choice and examined whether those children who regretted not waiting on the first day were more likely to delay gratification on the second day. In addition, we separately measured whether children in our sample were able to anticipate regret, using the task employed by McCormack and Feeney (2015; see also Guttentag \& Ferrell, 2008) that examined children's ability to predict their emotion on finding out that they had made a sub-optimal choice. This was to examine whether any association between regret and delayed gratification was likely to be due to the effect of being able to anticipate and avoid regret, rather than due to the experience of regret itself.

\section{Study 1}

\section{Method}

Participants. Seventy-eight 6-to-7-year-olds (41 females, $M=7$ years 3 months, Range $=6$ years 8 months- 7 years 9 months) participated. Children were tested individually in their schools. The sample size was similar to that used in previous studies that have found an association between the experience of regret and subsequent decision making in children (O'Connor et al., 2014); we also assumed that the majority of children would choose the short delay on Day 1 because they had no reason to believe that there was a better reward if 
they delayed. The study was approved by the Ethics Committee of the first author's department, and written parental permission was obtained for each child's participation.

Apparatus. Two colored boxes were used in the delayed gratification task. Each box had a red and a green light indicating whether the box was locked or unlocked respectively; unbeknownst to the participants the experimenter controlled the locks using a pocket remote control. There was also a small $9 \mathrm{~cm}$ sand-timer that took $30 \mathrm{~s}$ to empty and a large $16 \mathrm{~cm}$ sand-timer that lasted $600 \mathrm{~s}$. The short delay box contained two candies and the long delay box contained four candies; the relative value of the rewards was chosen on the basis of previous pilot work. Children's waiting times were timed using a stop watch. Three smaller white boxes were used in the anticipated regret task; each white box contained a smaller silver box with one token inside that could later be exchanged for a sticker. A five-point affective response scale was used, with each point illustrated by a cartoon face ranging from feeling "very sad" on the left to feeling "very happy". Children reported their emotional responses using this scale and a three-pronged arrow. The three-pronged arrow indicated changes in emotions during the game, with the leftward pointing arrow indicating feeling sadder than before, the rightward pointing arrow indicating feeling happier than before and the upward pointing arrow indicating feeling the same as before. The three-pronged arrow response mode has been used in a number of studies (e.g., O'Connor et al., 2012, 2014; Weisberg \& Beck, 2012); its important advantage is that it allows children to make a comparative emotional response even if they are already at the end point of the five-point scale. Two puppets with three small toys were also used in a pre-training phase.

Procedure. On Day 1 children were invited to play a short game. Children were introduced to the five-point scale, with the experimenter explaining the feeling that each face represented. The experimenter then named one of the feelings and asked children to point to the appropriate face. Next, children were introduced to the two puppets. The experimenter 
gave one puppet a toy and described the puppet as feeling "a little bit happy"; the other puppet received two toys and was described as feeling "very happy", using the scale. Both puppets then received one more toy and children were asked to use the three-pronged pointer to indicate whether the puppet now felt happier (rightward pointing arrow), sadder (leftward pointing arrow), or the same (upward pointing arrow). Children also witnessed the puppets losing their toys and were again asked to indicate how the puppet now felt. Children who gave inappropriate answers were corrected and the training was repeated; see O'Connor et al. (2012, Experiment 2) for full details of this training procedure.

Next, children were shown the red and yellow boxes and were told that each box contained a different prize and that they could choose one box to open up to get its prize; children were not told what the prizes were. The small $30 \mathrm{~s}$ sand-timer was placed beside the short delay box and the large 600 s sand-timer was placed beside the long delay box. The experimenter said that the boxes were currently locked, showing children the red light that was lit up on the front of each box. She explained that the sand-timers showed how long they would have to wait before each box unlocked, explaining that the green light on front of the box would light up when that box had unlocked. Children were asked which timer takes a shorter and which takes a longer time to empty. The experimenter then said: "You can choose to get the prize from the red box or the yellow box, but you can only get one of the prizes. When a green light is on and the red light is off you can open the box at any time and get the prize. Once the smaller sand-timer is finished you will be able to open this box and get the prize inside or you can wait until the bigger sand-timer is finished and get the prize inside this box. Remember, you can only get a prize from one box." The experimenter then turned over both sand-timers simultaneously.

After the $30 \mathrm{~s}$ sand-timer had emptied, she surreptitiously used the pocket remote control to unlock the short delay box; the lock made a clicking sound as it opened and the 
green light came on. If necessary, she also unlocked the long delay box after the $600 \mathrm{~s}$ sandtimer had emptied. Children chose to open one of the boxes to get its prize, with the experimenter using a stop-watch to time how long they took before deciding to open a box. During the waiting period, the experimenter sat in silence opposite the child; the experimenter was required to sit near the child in order to time their responses and to surreptitiously unlock the boxes using the pocket remote control once the delay period had elapsed, but did not engage with children. Children could see their prize as soon as they opened the box (two candies if they had chosen the short delay box; four candies if they had waited for the long delay box to open), and were asked to rate how they felt about their prize from their chosen box using the five-point scale. After children had given their response, the experimenter then opened the unchosen box (regardless of which box had been chosen) and children were asked to rate their feelings: "Here is how you said you felt earlier. Tell me how you feel about choosing your box now. Do you feel happier, sadder or the same?" Note that the use of the three-pronged arrow for this second comparative emotion rating yields categorical data (happier, sadder, or the same). Children were then given their candies and told that they could play the same game the following day.

On Day 2, children were presented with the same choice between boxes and the experimenter reminded them that exactly the same prizes were in the same boxes as on the previous day. The experimenter checked that children remembered that the boxes opened after different delays, and that the sand-timers showed the delay for each box. She explained that the game would work the same way as on the previous day, and that they could wait a short time to get the prize in the box with the small sand-timer or a long time to get the prize in the box with the large sand-timer. The task then proceeded in the same way as the previous day, although children did not make emotion ratings. 
The anticipated regret task, based on that of McCormack and Feeney (2014), was administered next. Children were shown the three white boxes and were told that inside the boxes were tokens that could be swapped for stickers at the end. Children were told that one box contained five tokens, one contained one token and the remaining box contained no tokens (whereas in reality all boxes contained just one token). Children were first asked to remove one box from the game before being asked to choose between the remaining two boxes for a prize, with it being made clear that they could only have the one prize from their chosen box. Regardless of which box was chosen, children won one token and were asked to rate how they felt on the five-point scale. The experimenter then pointed to the remaining box and asked the child to use the three-pronged arrow to indicate how they would feel if the remaining box contained five tokens or if it contained no tokens. The experimenter said "So, this is how you feel about choosing this prize. Now, you can't actually get the tokens in this other box (indicates unchosen box) but can you show me how you would feel if this box had five/no tokens in it? Would you feel happier, sadder or the same?" The ordering of these two questions was counterbalanced. Children swapped their one token for a sticker of their choice.

\section{Results and Discussion}

Delay of gratification task. The majority of children chose the short delay box on Day $1(73.1 \%, n=57)$. Of the 21 children who chose the long delay box, $4.8 \%(n=1)$ reported feeling sadder, 19\% $(n=4)$ reported feeling the same, and 76.2\% $(n=16)$ reported feeling happier after seeing the smaller prize in the short delay box. Of the children who chose the short delay box, $61.4 \%(n=35)$ reported feeling sadder, $26.3 \%(n=15)$ reported feeling the same, and $12.3 \%(n=7)$ reported feeling happier after seeing the better prize in the long delay box. A chi-squared test showed that there was a significant association between box choice and reported emotion, $\chi^{2}(2)=32.26, p<.001$, with children more likely 
to report feeling sadder if they had chosen the short delay box and happier if they had chosen the long delay box. Table 1 shows the numbers of children who felt sadder as function of children's box choice on Day 1 and also shows Day 2 box choices. 
Table 1. Children's Day 2 box choices as a function of children's Day 1 box choices and whether they reported feeling sadder on Day 1 about their choice.
Day 1 Choose Short
Day 1 Choose Long

\begin{tabular}{lcccc}
\cline { 2 - 5 } & Sadder & Not Sadder & Sadder & Not Sadder \\
\hline Day 2 Choose Short & 8 & 12 & 0 & 3 \\
Day 2 Choose Long & 27 & 10 & 1 & 17 \\
\hline
\end{tabular}

Overall, the majority of children chose the long delay box on Day $2(70.5 \%, n=55)$. The vast majority of children who chose the long delay box on Day 1 also chose the long delay box on Day $2(86 \%)$. The key analysis examined whether experiencing regret on Day 1 about choosing the short delay box, operationalized as feeling sadder on seeing the contents of the non-chosen box, was associated with delaying gratification on Day 2. Figure 1 shows the Day 2 box choices of children who chose the short delay box on Day 1, as a function of whether or not children experienced regret about their choice. For children who chose the short delay box on Day 1, a binary logistic regression was carried out with box choice on Day 2 as the outcome variable, and age in months and whether or not regret was experienced on Day 1 as the predictor variables. In a first step, we entered age in months as a predictor; this did not lead to a significantly better fit than the null model; $\chi^{2}(1)=0.10, p=.752$. In a second step, we added experiencing regret on Day 1 as a predictor; this led to a significant improvement in model fit, $\chi^{2}(1)=6.34, p=.012$. The final model is shown in Table 2 . 


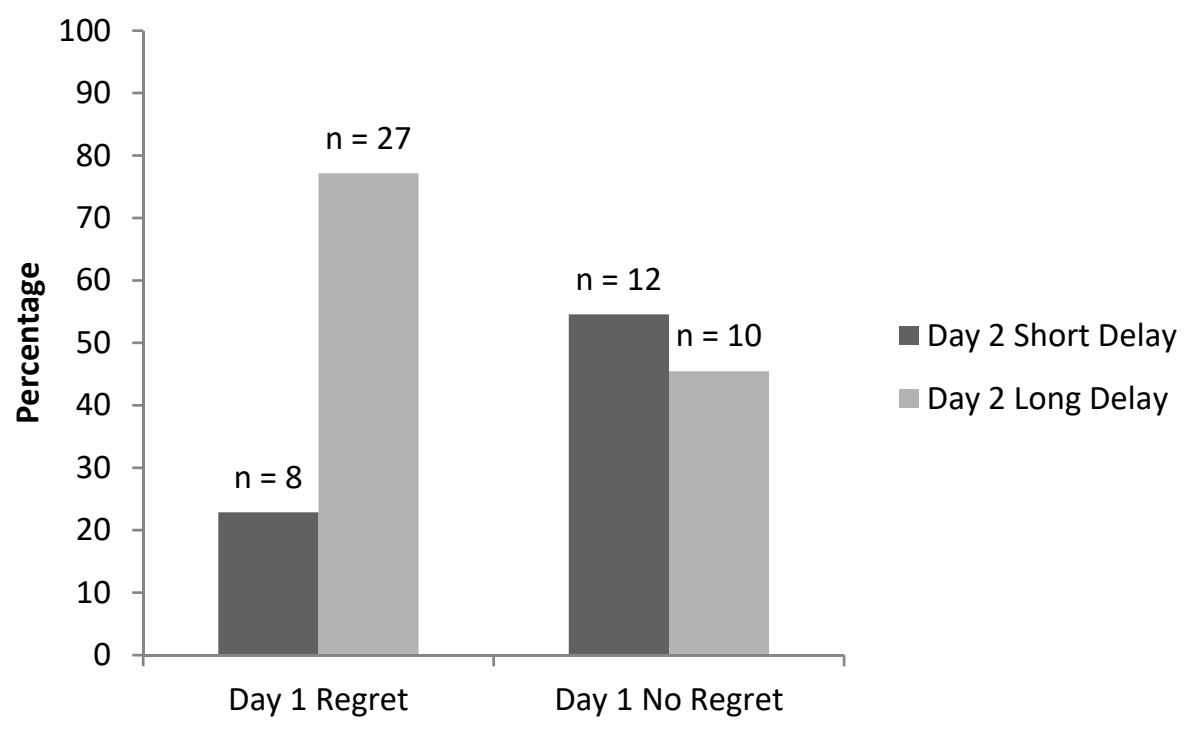

Figure 1. Percentage of children making each Day 2 box choice as a function of whether they had experienced regret about choosing the short delay box on Day 1; absolute numbers are given at the tops of the bars. Only children who chose the short delay box on Day 1 are included.

Table 2. Results of the binary logistic regression on Day 2 box choice with age in months and whether regret was experienced on Day 1 as predictor variables. Model $\chi^{2}(2)=6.44, p=.04$; Cox \& Snell $R^{2}=.11$, Nagelkerke $R^{2}=.15 .^{*} p=.015$

95\% CI for $\operatorname{EXP}(\mathrm{B})$

\begin{tabular}{lcccc} 
& B(SE) & Lower & EXP(B) & Upper \\
\hline Age (in months) & $0.07(0.10)$ & 0.89 & 1.07 & 1.28 \\
Regret on Day 1 & $1.48^{*}(0.61)$ & 1.34 & 4.38 & 14.32 \\
Constant & $-6.04(8.22)$ & & 0.01 & \\
\hline
\end{tabular}


Anticipated regret. A large majority of children, $88.5 \%(n=69)$, failed to report that that they would feel sadder about their box choice if the better prize was in the unchosen box. Similarly, $85.9 \%(n=67)$ of children did not answer that they would feel happier if the worse prize was in the other box. These results replicate previous studies (Guttentag \& Ferrell, 2008; McCormack \& Feeney, 2014) in suggesting that children within this age group are not yet capable of anticipating regret (or relief).

In summary, unsurprisingly given that they did not know the box with the longer delay contained a larger reward, most children chose the short delay box on Day 1. However, on Day 2, most children who had chosen the short delay box on the previous day now switched choices and chose to wait for the reward in the longer delay box. The key finding was that this was only the case for children who had previously experienced regret on seeing the larger reward in the unchosen long delay box. This finding suggests that the experience of regret was instrumental in helping children make a better choice on the second day. Replicating previous findings, in a separate task we showed that children in this study were unable to correctly anticipate under which circumstances they would experience regret, indicating that it was the experience of regret rather than the anticipation of this emotion that facilitated delayed gratification.

\section{Study 2}

This study aimed to rule out two less interesting possible explanations of the association observed in Study 1. First, it could be the case that some children did not prefer to receive four candies over two candies. Such children would not experience regret when, after winning two candies, they find out that they could have won four instead. These children also would have been likely to choose the short delay over the long delay box on Day 2, because the reward at the long delay was not more valuable to them. Second, it could be that children who are more intellectually able may report experiencing regret, and such children also find it 
easier to delay gratification. Although there is currently no evidence of a link between intelligence and the ability to experience regret, such an interpretation gains plausibility from some studies that have found associations between the ability to delay gratification and intelligence in children (e.g., Mischel \& Metzner, 1962; Rodriguez, Mischel, \& Shoda, 1989) and adults (Shamosh \& Gray, 2008).

\section{Method}

Participants. Seventy-four 6-to-7-year-olds (38 females, $M=7$ years 1 month, Range $=6$ years 4 months- 7 years 11 months) participated. The study was conducted in the same manner as in Study 1.

Apparatus and procedure. The apparatus and procedure were the same as Study 1. In addition, Raven's Standard Progressive Matrices (RPM, Raven, Raven, \& Court, 2000) was administrated to every child on Day 2. This is a widely used abbreviated measure of IQ that has been standardized on school-aged children and has been validated through its linkages with academic performance (e.g., Laidra, Pullmann, \& Allik, 2007; Pind, Gunnarsdóttir, \& Jóhannesson, 2003). In order to ensure children preferred winning more candies, a post-test question was included. Children were re-introduced to the two puppets and were told that one of the puppets really likes these candies and would prefer to have four instead of two, whereas the other puppet did not really like these candies and would prefer to only have two. Children were asked whether they were more like the puppet who likes four candies or the one who likes two candies.

\section{Results and Discussion}

Delay of gratification task. The data from four children ( 3 girls and 1 boy) were removed because their answers to the post-test question indicated that they did not prefer four over two candies, leaving a sample of 70 children (Mean age: 84.7 months, $S D=5.27$ ). As in Study 1 , the majority of children chose the short delay box on Day $1(77.1 \%, n=54)$. Of the 
16 children who chose the long delay box, $12.5 \%(n=2)$ reported feeling the same and $87.5 \%(n=14)$ reported feeling happier after seeing the worse prize in the short delay box. Of the 54 children who chose the short delay box, $66.7 \%(n=36)$ reported feeling sadder, $25.9 \%(n=14)$ reported feeling the same, and 7.4\% $(n=4)$ reported feeling happier after seeing the better prize in the long delay box. A chi-squared test showed that there was a significant association between box choice and reported emotion, $\chi^{2}(2)=41.70, p<.001$. Again, children who reported feeling sadder were classified as experiencing regret.

Table 3. Children's Day 2 box choices as a function of children's Day 1 box choices and whether they reported feeling sadder on Day 1 about their choice.

\begin{tabular}{lcccc}
\hline & \multicolumn{2}{c}{ Day 1 Choose Short } & \multicolumn{2}{c}{ Day 1 Choose Long } \\
\cline { 2 - 5 } & Sadder & Not Sadder & Sadder & Not Sadder \\
\hline Day 2 Choose Short & 3 & 7 & 0 & 2 \\
Day 2 Choose Long & 33 & 11 & 0 & 14 \\
\hline
\end{tabular}

The majority of children chose the long delay box on Day $2(82.9 \%, n=58)$. The vast majority of children who chose the long delay box on Day 1 also chose the long delay box on Day 2 (88\%); see Table 3. Again the key measure of interest was the relation between experiencing regret on Day 1 having chosen the short delay box, and delaying gratification on Day 2. Figure 2 shows that the vast majority (91.7\%) of children who experienced regret switched their choice to the long delay box on Day 2 compared with $61 \%$ of children who did not experience regret but also choice the long delay box on Day 2. A binary logistic regression was performed in order to assess whether experienced regret on Day 1 predicted delay of gratification on Day 2, with box choice on Day 2 as the outcome variable, and age in months, RPM score and whether regret was experienced as the predictor variables. In a first 
step, we entered age and RPM scores as predictor variables; this did not lead to a significantly improved fit over the null model, $\chi^{2}(2)=1.73, p=.421$. In a second step, we added whether participants experienced regret on Day 1 as a predictor; this improved fit significantly, $\chi^{2}(1)=8.52, p=.004$. Table 4 shows the final model fit.

Anticipated regret. The majority of children, $85.7 \%(n=60)$, did not predict that they would feel sadder about their box choice if the better prize was in the unchosen box. Similarly, $88.6 \%(n=62)$ of children did not predict that they would feel happier if the worse prize was in the other box.

These results replicated those of Study 1 in showing that children who experienced regret about not waiting for a delay to get a reward were more likely to delay gratification when given the option a day later. This was the case even when controlling for intellectual ability, and we also ensured that all children included in the analysis had a preference for the larger reward. As in Study 1, the link between regret and delaying gratification does not appear to be due to the ability to anticipate regret, as the majority of children were unable to anticipate this emotion in the separate anticipated regret task. We note that intellectual ability was not predictive of delayed gratification in our study. The most systematic analysis of this link to date is the meta-analysis of studies with both children and adults conducted by Shamosh and Gray (2008); although the meta-analysis does indeed support the idea of a link between intelligence and delay of gratification, they also report considerable variability between studies (and there is also variability within studies depending on the intelligence measure examined; e.g., Hongwanishkul et al., 2005). We note that in our sample there was a significant correlation between age and raw RPM scores, $r(74)=.443, p<.001$, indicating that the intelligence measure was successfully picking up individual differences. 


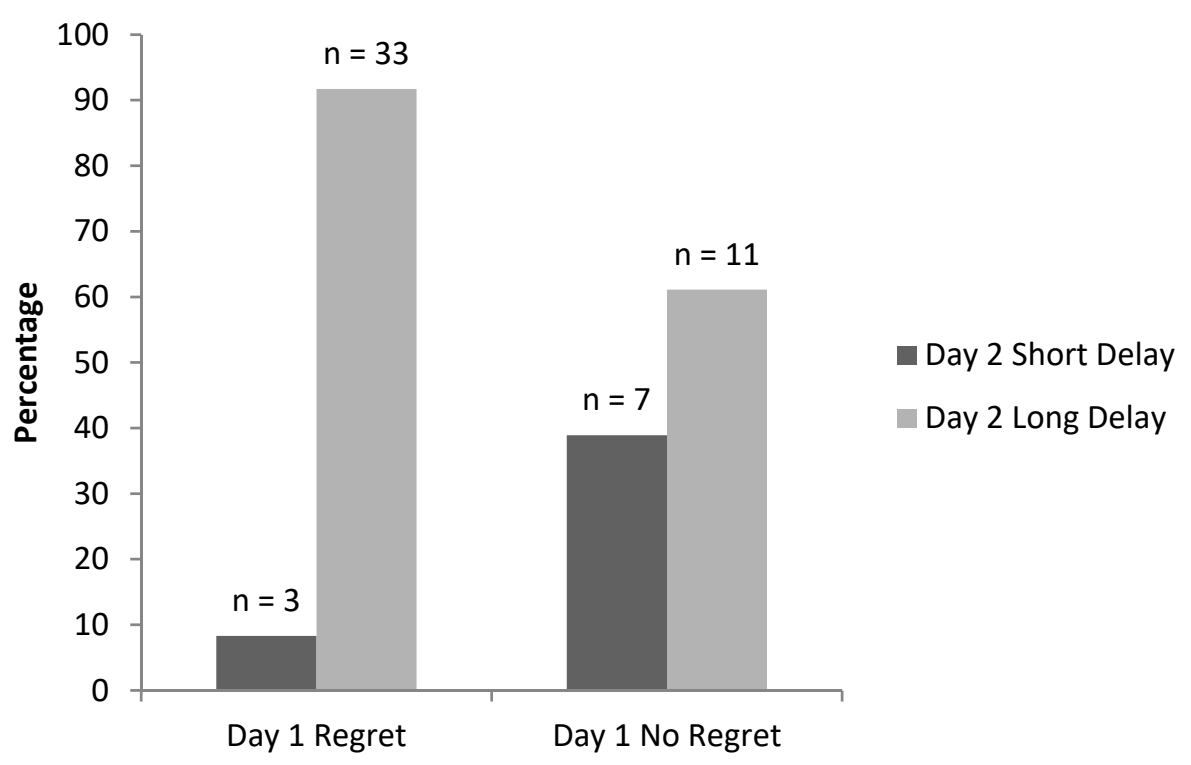

Figure 2. Percentage of children making each Day 2 box choice as a function of whether they had experienced regret about choosing the short delay box on Day 1; absolute numbers are given at the tops of the bars. Only children who chose the short delay box on Day 1 are included.

Table 2. Results of the binary logistic regression on Day 2 box choice with age in months, raw RPM scores, and whether regret was experienced on Day 1 as predictor variables. Model $\chi^{2}(3)=10.25, p=.017$; Cox \& Snell $R^{2}=.17$, Nagelkerke $R^{2}=.28 . * p=.007$.

$95 \%$ CI for $\operatorname{EXP}(\mathrm{B})$

\begin{tabular}{lcccc} 
& B(SE) & Lower & EXP(B) & Upper \\
\hline Age (in months) & $0.03(0.09)$ & 0.86 & 1.03 & 1.22 \\
RPM score & $0.20(0.14)$ & 0.92 & 1.22 & 1.61 \\
Regret on Day 1 & $2.28^{*}(0.85)$ & 1.87 & 9.81 & 51.49 \\
Constant & $-6.52(6.87)$ & & 0.001 & \\
\hline
\end{tabular}




\section{General Discussion}

The novel finding in this study is its demonstration of an association between experiencing regret after failing to wait for a reward and delaying gratification when faced a second time with the same choice between immediate or delayed reward. We interpret this association as indicating that the experience of regret helps children learn to delay gratification when asked to choose again. The most common way in which delayed gratification has been linked with emotional development is in terms of the idea that it requires emotion regulation (e.g., Kim et al., 2013; Kochanska, Murray, \& Harlan, 2000; Metcalfe \& Mischel, 1999). In this context, the general idea has been that what is required for delayed gratification is the ability to suppress a salient emotional response to a reward, which has typically been conceptualized as one aspect of control processes (Casey et al., 2011;

Duckworth \& Steinberg, 2015). Predictive relations between the ability to delay gratification and long-term behavioral outcomes have been explained in terms of delay of gratification tasks measuring a developmentally important aspect of self-regulation (e.g., Casey et al., 2011; Duckworth, Tsukayama, \& Kirby, 2013; Kim et al., 2013). While this may be correct, our data suggest an alternative way of thinking about how emotional development is linked with delay of gratification, in which emotional experience - specifically regret - plays a positive role.

The idea that experiencing regret can act as a mechanism to help children to learn quickly to make better choices is in line with existing theorizing about the function of experienced regret that emphasizes its role in decision making (Zeelenberg \& Pieters, 2007). It is consistent with Zeelenberg and Pieters's (2007) suggestion that the process of mental undoing involved in experiencing regret, and the accompanying emotion that arises as a result, makes salient the alternative course of action (in this case, waiting longer for a better reward), facilitating the selection of this course of action when faced with the same or a 
similar choice again. Importantly, such a mechanism could operate without children actually being able to anticipate future regret when asked to choose: the findings of both experiments in the separate task assessing the ability to anticipate regret indicated that children of the age tested in this study were not able to anticipate this counterfactual emotion, consistent with previous findings (McCormack \& Feeney, 2015). This suggests that it was the emotional experience itself that impacted on subsequent behavior.

Note, though, that we are not claiming that it is necessary to experience regret over failing to wait in order to be able to delay gratification. For a start, when faced with a choice, many children who are not old enough to experience regret will choose to delay gratification in some situations (e.g., Atance \& Jackson, 2009; Metcalf \& Atance, 2011; Thompson, Barresi, \& Moore, 1997). Thus, clearly, children can learn to wait without necessarily experiencing regret about a failure to wait. Our claim is that experiencing regret can help children learn rapidly to make more adaptive choices, and in particular help children spontaneously bring to mind what the best course of action is when faced with a choice (O'Connor et al., 2014), rather than that good decision making always requires the ability to experience regret.

There is of course a crucial difference between the nature of the choice that faced children on Day 2 versus that which they faced on Day 1, which is that children knew the box contents on the second day but not the first. Did children learn to delay gratification on Day 2 because they were provided with information they did not possess on Day 1 about the box contents? Importantly, simply being provided with this information did not guarantee that children chose to wait: if this had been the only reason for the increase in the number of children delaying gratification, then children who did not experience regret on Day 1 would have been as likely to delay gratification on Day 2 as those who did experience regret. Study 2 ruled out the possibility that this difference in behavior between regretters and non- 
regretters was due to differences in intelligence or in the likelihood of preferring the larger over the smaller reward. Thus, although possessing information about box contents clearly increased the likelihood that children would wait longer to get a reward (even in nonregretters), the availability of this new information does not explain group difference between the regretters and non-regretters.

We recognize, though, that the association we find between Day 1 emotion experience and Day 2 choice might potentially not reflect a causal link between these two variables. It could be that children assume that because they report feeling sadder about their box choice on Day 1, they should appear consistent in their choices to the experimenter and thus choose the long delay box on Day 2. Such a suggestion would potentially be compatible with recent research indicating that even young children engage in (at least basic types) of impression management (see Silver \& Shaw, 2018, for review). However, we note that if impression management underpins the association between regret on Day 1 and box choice on Day 2, children's Day 2 box choices would have to be primarily driven by a wish to appear consistent to the experiment rather than a sensitivity to the reward structure in the task. Moreover, a quite sophisticated notion of consistency would be required: children would need to believe that appearing most consistent would not be a matter of making the same choice that they did the previous day (i.e., choosing the short delay box again) but of choosing a different box because such a choice would appear to the experimenter to be compatible with their reported emotions on Day 1. We know of no evidence to suggest that young children grasp this more sophisticated notion of consistency, or that they would feel compelled to adhere to a social norm associated with consistency, nor that it would override any other motivations in a situation in which children have to make choices involving concrete attractive rewards. Nevertheless, this possibility could be straightforwardly ruled out by using different experimenters across the two days of testing. 
Perhaps more plausibly, there could be a third factor not picked up by our IQ measure that separately influences whether children experience regret and whether children delay gratification. For example, recent studies have emphasized the role of social context, in particular family and parenting factors, in the development of the ability to delay gratification (e.g., Lamm et al. 2017; Razza \& Raymond, 2013; Sturge-Apple, Davies, Cicchetti, Hentges, $\&$ Coe, 2017). We do not have any knowledge about how such factors might affect the development of regret, but families differ in the extent to which they discuss and express emotions, impacting on children's emotional development (e.g., Denham \& Kochanoff, 2002; Perlman, Camras, \& Pelphrey, 2008). The current study cannot rule out the possibility that such factors might play a role in explaining the association we have observed between regret and delay of gratification. Establishing that the link is a causal one would potentially require manipulating the likelihood that children experience regret and examining the effect that this might have on their tendency to delay gratification; e.g., drawing children's attention to the reward differential when the contents of the unchosen box are revealed might potentially impact on the likelihood that children feel regret and on subsequent delay of gratification.

In line with a number of studies that have used related types of procedures (e.g., O’Connor et al., 2012, 2014; Weisberg \& Beck, 2010, 2012, Van Duijvenvoorde et al., 2014) we have described the emotion we have measured as regret. Although children are asked to describe only the valence of their emotional change in our procedure (i.e., happier, sadder, or the same), this emotion change is in response to the provision of counterfactual information (i.e., information about what they would have received had they made a different choice). Studies examining regret in adults and adolescents use more complex choice tasks (typically involving decisions about options varying in risk), but very similar methods of assessing regret (i.e., in terms of the valence change of emotion following exposure to counterfactual information, using an emotion scale, e.g., Camille et al., 2004; Habib et al., 2012). That is, as 
with the studies with children, adult experimental studies of regret also ask participants to report simply on the valence of their emotions when provided with information about a counterfactual that would have obtained if they had made a different choice. Evidence that these ratings should be interpreted as reflecting distinctive counterfactual emotions comes from studies that indicate that there are particular types of neuropsychological patients who seem to be capable of experiencing simpler emotions that do not involve counterfactual thought but show specific impairments in reporting changes in emotion when provided with counterfactual information (Camille et al., 2004; Coricelli, Dolan, \& Sirigu, 2007).

Neuroimaging studies suggest that these latter emotions also seem to recruit distinctive brain regions (Coricelli et al., 2007).

We acknowledge, though, there has been some previous debate over whether it is safe to assume that children's responses reflect regret; in particular, Rafetseder and Perner (2012) have argued that children may be simply frustrated that they do not currently have the best available prize, and suggest that such frustration need not be underpinned by counterfactual thought. Three lines of evidence suggest that simple frustration of this sort is not the emotion underpinning children's responses in this type of choice procedures: first, whether children report feeling sad is moderated by their level of responsibility in determining the outcome (O’Connor, McCormack, Beck, \& Feeney, 2015; Weisberg \& Beck, 2012), which would be predicted if regret was the underpinning emotion. Second, children also report feeling sad after receiving the relevant counterfactual information even if they already know they have not got the best available prize (McCormack, O’Connor, Beck, \& Feeney, 2016). Third, when children are asked to provide explanations of their reported change in emotions, the majority of 6- to 7-year-olds make explicit reference to the counterfactual prize, and around a third of children use counterfactual language in their explanations (O'Connor et al., 2012). Thus, the available evidence suggests that it is plausible to assume that our task measures regret. 
The developmental emergence of regret has a cognitive underpinning: it depends upon actively comparing an actual outcome with a counterfactual outcome that could have been obtained if one had made a different decision. Thus, the important developmental changes must be both cognitive and emotional. We conceptualize this interplay between cognitive and emotional development as setting up a "virtuous circle" that improves the quality of children's decisions. That is, cognitive changes can result in new types of emotional experiences, which in turn can contribute to the development of flexible controlled behavior. As discussed in the introduction, experiencing regret requires the ability to think counterfactually about the outcome that would have obtained if one had chosen differently. There is some evidence to suggest that the emergence of counterfactual thought may be linked to aspects of preschoolers' executive functioning such as working memory and representational flexibility (Drayton et al., 2011; Guajardo, Parker, \& Turley-Ames, 2009). Once counterfactual thinking has emerged, the further ability to experience regret, which requires evaluatively comparing actual and counterfactual outcomes, has been linked to attentional flexibility (Burns et al., 2012). Thus, cognitive aspects of control processes contribute to the development of regret itself.

Our suggestion is that once regret is established in children's emotional repertoire, it can then impact on the quality of children's decisions, resulting in behavior that is more controlled and less impulsive. The current findings provide initial evidence for this suggestion, and fit with the idea that regret, although unpleasant, is a functional emotion that has beneficial effects on behavior (Roese, 2004; Zeelenberg \& Pieters, 2007). Future developmental research could examine the contexts in which regret does indeed impact on children's choices. 


\section{References}

Atance, C. M., \& Jackson, L. K. (2009). The development and coherence of future-oriented behaviors during the preschool years. Journal of Experimental Child Psychology, 102(4), 379-391. doi:10.1016/j.jecp.2009.01.001

Beck, S. R., \& Riggs, K. J. (2014). Developing thoughts about what might have been. Child Development Perspectives, 8(3), 175-179. doi:10.1111/cdev.12082

Beck, S. R., Riggs, K. J., \& Burns, P. (2011). Multiple developments in counterfactual thinking. In C. Hoerl, T. McCormack, \& S. R. Beck (Eds.), Understanding counterfactuals, understanding causation (pp. 110-122). Oxford: Oxford University Press.

Burns, P., Riggs, K. J., \& Beck, S. R. (2012). Executive control and the experience of regret. Journal of Experimental Child Psychology, 111(3), 501-515. doi:10.1016/j.jecp.2011.10.003

Camille, N., Coricelli, G., Sallet, J., Pradat-Diehl, P., Duhamel, J.-R., \& Sirigu, A. (2004). The involvement of the orbitofrontal cortex in the experience of regret. Science, 304(5674), 1167-1170. doi:10.1126/science.1094550

Casey, B. J., Somerville, L. H., Gotlib, I. H., Ayduk, O., Franklin, N. T., Askren, M. K., et al. (2011). Behavioral and neural correlates of delay of gratification 40 years later. Proceedings of the National Academy of Sciences of the United States of America, 108(36), 14998-15003. doi:10.1073/pnas.1108561108

Connolly, T., \& Zeelenberg, M. (2002). Regret in decision making. Current Directions in Psychological Science, 11(6), 212-216. doi:10.1111/1467-8721.00203

Coricelli, G., Critchley, H. D., Joffily, M., O’Doherty, J. P., Sirigu, A., \& Dolan, R. J. (2005). Regret and its avoidance: A neuroimaging study of choice behaviour. Nature Neuroscience, 8(9), 1255-1262. doi:10.1038/nn1514 
Coricelli, G., Dolan, R. J., Sirigu, A. (2007). Brain, emotion, and decision making: The paradigmatic example of regret. Trends in Cognitive Sciences, 11(6), 258-265. doi:10.1016/j.tics.2007.04.003

Denham, S., \& Kochanoff, A. T. (2002). Parental contributions to preschoolers' understanding of emotion. Marriage \& Family Review, 34, 311-343. doi: 10.1300/J002v34n03_06

Drayton, S., Turley-Ames, K. J., \& Guajardo, N. R. (2011). Counterfactual thinking and false belief: The role of executive function. Journal of Experimental Child Psychology, 108(3), 532-548. doi:10.1016/j.jecp.2010.09.007

Duckworth, A. L., \& Steinberg, L. (2015). Unpacking self-control. Child Development Perspectives, 9(1), 32-37. doi:10.1111/cdep.12107

Duckworth, A. L., Tsukayama, E., \& Kirby, T. A. (2013). Is it really self-control? Examining the predictive power of the delay of gratification task. Personality and Social Psychology Bulletin, 39(7), 843-855. doi:10.1177/0146167213482589

Feeney, A., Travers, E., O’Connor, E., Beck, S. R., \& McCormack, T. (2018). Knowing when to hold 'em: Regret and the relation between missed opportunities and risk taking in children, adolescents and adults. Cognition and Emotion, 32, 608-615. doi: $10.1080 / 02699931.2017 .1326373$

Ferrell, J. M., Guttentag, R. E., \& Gredlein, J. M. (2009). Children's understanding of counterfactual emotions: Age differences, individual differences, and the effects of counterfactual-information salience. British Journal of Developmental Psychology, 27, 569-585. doi:10.1348/026151008x337743

German, T. P., \& Nichols, S. (2003). Children's counterfactual inferences about long and short causal chains. Developmental Science, 6(5), 514-523. doi:10.1111/1467- 
7687.00309

Guajardo, N. R., Parker, J., \& Turley-Ames, K. (2009). Associations among false belief understanding, counterfactual reasoning, and executive function. British Journal of Developmental Psychology, 27, 681-702. doi:10.1348/026151008x357886

Guttentag, R., \& Ferrell, J. (2008). Children's understanding of anticipatory regret and disappointment. Cognition \& Emotion, 22(5), 815-832. doi:10.1080/02699930701541542

Habib, M., Cassotti, M., Borst, G., Simon, G., Pineau, A., Houdé, O., \& Moutier, S. (2012). Counterfactually mediated emotions: A developmental study of regret and relief in a probabilistic gambling task. Journal of Experimental Child Psychology, 112(2), 265274. doi:10.1016/j.jecp.2012.01.007

Harris, P. L., German, T., \& Mills, P. (1996). Children's use of counterfactual thinking in causal reasoning. Cognition, 61(3), 233-259. doi:10.1016/s0010-0277(96)00715-9

Hongwanishkul, D., Happaney, K. R., Lee, W. S. C., \& Zelazo, P. D. (2005). Assessment of hot and cool executive function in young children: Age-related changes and individual differences. Developmental Neuropsychology, 28(2), 617-644. doi:10.1207/s15326942dn2802 4

Jahromi, L. B., \& Stifter, C. A. (2008). Individual differences in preschoolers' self-regulation and theory of mind. Merrill-Palmer Quarterly-Journal of Developmental Psychology, 54(1), 125-150. doi:10.1353/mpq.2008.0007

Kim, S., Nordling, J. K., Yoon, J. E., Boldt, L. J., \& Kochanska, G. (2013). Effortful control in "hot" and "cool" tasks differentially predicts children's behavior problems and academic performance. Journal of Abnormal Child Psychology, 41(1), 43-56. doi:10.1007/s10802-012-9661-4

Kochanska, G., Murray, K. T., \& Harlan, E. T. (2000). Effortful control in early childhood: 
Continuity and change, antecedents, and implications for social development. Developmental Psychology, 36(2), 220-232. doi:10.1037//0012-1649.36.2.220

Laidra, K., Pullmann, H., \& Allik, J. (2007). Personality and intelligence as predictors of academic achievement: A cross-sectional study from elementary to secondary school. Personality and Individual Differences, 42, 441-451. doi: 10.1016/j.paid.2006.08.001

Lamm, B., Keller, H., Teiser, J., Gudi, H., Yovsi, R. D., Freitag, C., et al. (2018). Waiting for the second treat: developing culture-specific modes of self-regulation. Child Development, 8, 261-277. doi: 10.1111/cdev.12847

Larrick, R. P., \& Boles, T. L. (1995). Avoiding regret in decisions with feedback - a negotiation example. Organizational Behavior and Human Decision Processes, 63(1), 87-97. doi:10.1006/obhd.1995.1064

Marchetti, A., Castelli, I., Sanvito, L., \& Massaro, D. (2014). Is a bird in the hand worth two in the future? Intertemporal choice, attachment and theory of mind in school-aged children. Frontiers in Psychology, 5. doi:10.3389/fpsyg.2014.00483

McCormack, T., \& Feeney, A. (2015). The development of the experience and anticipation of regret. Cognition and Emotion, 29(2), 266-280. doi:10.1080/02699931.2014.912201

McCormack, T., O’Connor, E., Beck, S. R., \& Feeney, A. (2016). The development of regret and relief for the outcomes of risky decisions. Journal of Experimental Child Psychology, 148, 1-19. doi: 10.1016/j.jecp.2016.02.008

Mellers, B., Schwartz, A., \& Ritov, I. (1999). Emotion-based choice. Journal of Experimental Psychology-General, 128(3), 332-345. doi:10.1037//0096-3445.128.3.332

Metcalf, J. L., \& Atance, C. M. (2011). Do preschoolers save to benefit their future selves? Cognitive Development, 26(4), 371-382. doi:10.1016/j.cogdev.2011.09.003

Metcalfe, J., \& Mischel, W. (1999). A hot/cool-system analysis of delay of gratification: Dynamics of willpower. Psychological Review, 106(1), 3-19. doi:10.1037/0033- 
295x.106.1.3

Mischel, W. (2014). The Marshmallow Test: understanding self-control and how to master it. New York: Little, Brown and Company.

Mischel, W., Ayduk, O., Berman, M. G., Casey, B. J., Gotlib, I. H., Jonides, J., Kross, E., Teslovich, T., Wilson, N. L., Zayas, V., \& Shoda, Y., 2010. 'Willpower'over the life span: decomposing self-regulation. Social Cognitive and Affective Neuroscience, 6, 252-256. doi: 10.1093/scan/nsq081

Mischel, W., \& Metzner, R. (1962). Preference for delayed reward as a function of age, intelligence, and length of delay interval. The Journal of Abnormal and Social Psychology, 64(6), 425-431.

Mischel, W., Shoda, Y., \& Rodriguez, M. L. (1989). Delay of gratification in children. Science, 244(4907), 933-938. doi:10.1126/science.2658056

Moore, B. S., Clyburn, A., \& Underwood, B. (1976). Role of affect in delay of gratification. Child Development, 47(1), 273-276. doi:10.2307/1128312

O'Connor, E., McCormack, T., \& Feeney, A. (2012). The development of regret. Journal of Experimental Child Psychology, 111(1), 120-127. doi:10.1016/j.jecp.2011.07.002

O'Connor, E., McCormack, T., \& Feeney, A. (2014). Do children who experience regret make better decisions? A developmental study of the behavioral consequences of regret. Child Development, 85(5), 1995-2010. doi:10.1111/cdev.12253

O’Connor, E., McCormack, T., Beck, S., \& Feeney, A. (2015). Regret and adaptive decision making in young children. Journal of Experimental Child Psychology, 135, 86-92. 10.1016/j.jecp.2015.03.003

Perlman, S. B., Camras, L. A., \& Pelphrey, K. A. (2008). Physiology and functioning: Parents' vagal tone, emotion socialization, and children's emotion knowledge. Journal of Experimental Child Psychology, 100, 308-315. doi: 
10.1016/j.jecp.2008.03.007

Pind, J., Gunnarsdóttir, E. K., \& Jóhannesson, H. S. (2003). Raven's Standard Progressive Matrices: new school age norms and a study of the test's validity. Personality and Individual Differences, 34, 375-386. doi: 10.1016/S0191-8869(02)00058-2

Rafetseder, E., \& Perner, J. (2012). When the alternative would have been better: Counterfactual reasoning and the emergence of regret. Cognition and Emotion, 26(5), 800-819. doi:10.1080/02699931.2011.619744

Rafetseder, E., \& Perner, J. (2014). Counterfactual reasoning: sharpening conceptual distinctions in developmental studies. Child Development Perspectives, 8(1), 54-58. doi:10.1111/cdep.12061

Razza, R. A., \& Raymond, K. (2013). Associations among maternal behavior, delay of gratification, and school readiness across the early childhood years. Social Development, 22, 180-196. doi: 10.1111/j.1467-9507.2012.00665.x

Rodriguez, M. L., Mischel, W., \& Shoda, Y. (1989). Cognitive person variables in the delay of gratification of older children at risk. Journal of Personality and Social Psychology, 57(2), 358-367. doi: 10.1037/0022-3514.57.2.358

Roese, N. (2005). If only: How to turn regret into opportunity. New York: Broadway Books.

Shamosh, N. A., Gray, J. R. (2008). Delay discounting and intelligence: a meta-analysis. Intelligence, 36(4), 289-305. doi: 10.1016/j.intell.2007.01.004

Shimoni, E., Asbe, M., Eyal, T., \& Berger, A. (2016). Too proud to regulate: The differential effect of pride versus joy on children's ability to delay gratification. Journal of Experimental Child Psychology, 141, 275-282. doi:10.1016/j.jecp.2015.07.017

Silver, I. M., \& Shaw, A. (2018). Pint-sized public relations: the development of reputation management. Trends in Cognitive Sciences, 22, 277-279. doi: 
Sobel, D. M. (2011). Knowledge and children's reasoning about possibility. In C. Hoerl, T. McCormack, \& S. R. Beck (Eds.), Understanding counterfactuals, understanding causation (pp. 123-146). Oxford: Oxford University Press.

Sturge-Apple, M. L., Davies, P. T., Cicchetti, D., Hentges, R. F., \& Coe, J. L. (2017). Family instability and children's effortful control in the context of poverty: Sometimes a bird in the hand is worth two in the bush. Development and Psychopathology, 29, 685-696. doi: $10.1017 / \mathrm{S} 0954579416000407$

Thompson, C., Barresi, J., \& Moore, C. (1997). The development of future-oriented prudence and altruism in preschoolers. Cognitive Development, 12(2), 199-212. doi:10.1016/s0885-2014(97)90013-7

Tobin, R. M., \& Graziano, W. G. (2010). Delay of gratification: A review of fifty years of regulation research. In R. H. Hoyle (Ed.), Handbook of personality and selfregulation (pp. 47-63). Chichester, West Sussex, UK: Blackwell.

Uprichard, B., \& McCormack, T. (2018). Becoming kinder: prosocial choice and the development of interpersonal regret. Child Development. doi: 10.1111/cdev.13029

Van Duijvenvoorde, A. C. K., Huizenga, H. M., \& Jansen, B. R. J. (2014). What is and what could have been: Experiencing regret and relief across childhood. Cognition \& Emotion, 28(5), 926-935. doi:10.1080/02699931.2013.861800

Weisberg, D. P., \& Beck, S. R. (2010). Children's thinking about their own and others' regret and relief. Journal of Experimental Child Psychology, 106(2-3), 184-191. doi:10.1016/j.jecp.2010.02.005

Weisberg, D. P., \& Beck, S. R. (2012). The development of children's regret and relief. Cognition and Emotion, 26(5), 820-835. doi:10.1080/02699931.2011.621933

Weisberg, D. S., \& Gopnik, A. (2013). Pretense, counterfactuals, and Bayesian causal models: why what is not real really matters. Cognitive Science, 37(7), 1368-1381. 
doi:10.1111/cogs.12069

Welsh, M., \& Peterson, E. (2014). Issues in the conceptualization and assessment of hot executive functions in childhood. Journal of the International Neuropsychological Society, 20(2), 152-156. doi:10.1017/s1355617713001379

Yates, G. C. R., Lippett, R. M. K., \& Yates, S. M. (1981). The effects of age, positive affect induction, and instructions on children's delay of gratification. Journal of Experimental Child Psychology, 32(1), 169-180. doi:10.1016/0022-0965(81)90101-6

Yu, J. H., Kam, C. M., \& Lee, T. M. C. (2016). Better working memory and motor inhibition in children who delayed gratification. Frontiers in Psychology, 7. doi:10.3389/fpsyg.2016.01098

Zeelenberg, M. (1999). Anticipated regret, expected feedback and behavioral decision making. Journal of Behavioral Decision Making, 12(2), 93-106. doi:10.1002/(sici)1099-0771(199906)12:2<93::aid-bdm311>3.0.co;2-s

Zeelenberg, M., \& Pieters, R. (2007). A theory of regret regulation 1.0. Journal of Consumer Psychology, 17(1), 3-18. doi:10.1207/s15327663jcp1701_3

Zeelenberg, M., van Dijk, W. W., Manstead, A. S. R., \& van der Pligt, J. (2000). On bad decisions and disconfirmed expectancies: The psychology of regret and disappointment. Cognition and Emotion, 14(4), 521-541. doi: $10.1080 / 026999300402781$

Zelazo, P. D., \& Carlson, S. M. (2012). Hot and cool executive function in childhood and adolescence: development and plasticity. Child Development Perspectives, 6(4), 354360. doi:10.1111/j.1750-8606.2012.00246.x

Zelazo, P. D., Qu, L., \& Muller, U. (2005). Hot and cool aspects of executive function: Relations in early development. In W. Schneider, R. Schumann-Hengsteler, \& B. Sodian (Eds.), Young children's cognitive development: interrelationships among 
executive functioning, working memory, verbal ability, and theory of mind (pp. 7193). London: Psychology Press. 